\title{
Peertechz
}

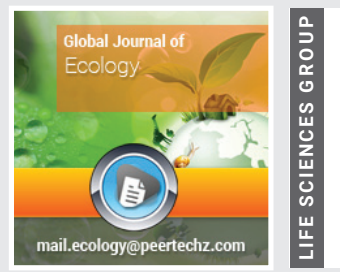

\section{Impacts of Climatic Factors on Vegetation Species Diversity, Herbaceous Biomass in} Borana, Southern Ethiopia

Received: 28 July, 2020

Accepted: 12 August, 2020

Published: 13 August, 2020

*Corresponding author: Asfaw EJO, Oromia Agricultural Research Institute, Yabello Pastoral and Dryland Agriculture Research Center, P.0 Box 85, Yabello,

Ethiopia, Tel: +251913783756;

Email:whyman12h@gmail.com

Keywords: Rangeland types; Species diversity and richness; Herbaceous biomass and rainfall

https://www.peertechz.com

Check for updates

\author{
Asfaw EJO*, Tessema Zewedu and Ibsa Aliyi Usmane \\ Oromia Agricultural Research Institute, Yabello Pastoral and Dryland Agriculture Research Center, P.O \\ Box 85, Yabello, Ethiopia
}

\begin{abstract}
The study was conducted in three districts of Borana Zone, with the objective to determining the impacts of climatic factors on vegetation species diversity, herbaceous biomass yield of Borana rangelands under commonial grazing rangeland types during end of growing season. The most types rangeland of communial properties are traditional enclosure and continuous grazing rangeland from in where our different data were collected. Within both rangeland types of each districts $20 \mathrm{~m}$ $\times 20 \mathrm{~m}$ plots that placed at $200 \mathrm{~m}$ distances intervals with three replication was used to collect woody vegetation. The data of herbaceous plant community was collected from seventeen quadrants $(1 \mathrm{~m} \times 1 \mathrm{~m})$ that layout in the main plot. The collected data was analyzed by linear regression to determine the impact of climate factors. The herbaceous species richness, diversity and biomass study sites had highly significantly difference $(P<0.001)$ and positive linear with mean annual precipitation. There is significantly difference $(\mathrm{P}<0.05)$ and negative linear in woody species richness and diversity. Both herbaceous and woody plant species richness and diversity of study areas had a negative linear with mean annual temperature. Climate factors specieally rianfall have a great impact on semi-arid rangeland ecosystems of study areas. Therefore, semi-arid rangeland user should be considering climatic factors to improve productivity of rangeland at semi-arid enviroments.
\end{abstract}

\section{Introduction}

In the world, rangeland is taking place the largest total landmass as compared to other types of terrestrial [1], while in threat due to impacts of climatic factors. Since climatic change encourages the reduction of rangeland productivity through increased frequency and intensity of floods and droughts, and the loss of many biodiversities. In the arid zone, climate events especially rainfall have a greater impact on rangeland productivity than grazing.

In Ethiopia nation of Oromia regional rangeland, Borana rangeland is the largest and have many renewable natural resources/ecosystem while they were exposer to climate variability. Bassi and Tache (2008) stated that the pastoral production system in Borana rangeland depends on the availability of range resources that depend on seasonal variability. Nowadays the rate of rangeland resource degradation increase even many research institutions and development organizations and individuals had been involved to solve several problems. Environmental circumstances and management practices are playing a crucial role in describing the function and distribution of rangeland vegetation species because they are governed by the nature and productivity of rangeland ecosystems [2]. Hoffman and Vogel [3], reported that climate factors such as rainfall, temperature, and atmospheric carbon dioxide concentration are the main factors to alter rangeland resource productivity in terms of qualitative and quantitative outputs. So understanding vegetation response to climatic factors is crucial to facilitate the manipulation of arid and semi-arid regions of natural resource conservation for sustainable use [4].

Nevertheless, the effort made so far was not satisfactory and the community who intensively depend on Borana rangelands have been vulnerable to a serious livestock feed shortage which resulted due to the gradual replacement of highly desirable species by fewer desirables species. Thus studies are necessary 
to investigate the response of rangeland vegetation to climatic factors, especially in arid and semi-arid regions of the ecosystem. As a result, further study and understanding of the interrelationships of rangeland ecosystems related to climatic factors are the most important tools to approve appropriate management measures in rangeland areas. While it had less consideration in study areas during rangeland administration and utilization of rangeland resources. Hence, this study designed to generate information with the general objective of evaluating the current species diversity and herbaceous biomass under traditional enclosures and continuously grazed rangelands in relation to climatic factors to develop mitigation and adaptation strategies in Borana rangelands, southern Ethiopia.

\section{Specific objectives}

To assess the effect of climatic factors on plant species diversity and herbaceous biomass of semi-arid rangeland in selected districts of Borana zone.

\section{Material and methods}

\section{Description of the study area}

The study was conducted at Yabello, Arero and Teltele districts of Borana zone, Southern Ethiopia. Yabello is located at a distance of $563 \mathrm{~km}$ from Addis Ababa in the southern part of Ethiopia. Arero and Teltele are located at equidistant (100 $\mathrm{km}$ ), each to east and west of Yabello town respectively Figure

\section{Climate features}

Rainfall: The climate of study areas has bimodal nature of rainfall namely long (60\%) and short ( $27 \%)$ intensity rain season which falling between March and May and falling between September and November respectively with $16.80^{\circ} \mathrm{C}$ of the minimum and $29.08{ }^{\circ} \mathrm{C}$ of the maximum annual mean temperature. The current 17 years (2001 to 2017) rainfall of study areas of the growing season (long and short rainy season) collected by the National Meteorological Services Agency of Ethiopia were highlighted in Table 1. For two sequence years (2016 and 2017) the ground status of semi-arid rangeland vegetation was collected in both growing seasons. At all study sites, the growing season rainfall of 2016 was lower than the mean growing season rainfall of 2001-2017, but in 2017 it was approximately the same as total average growing season rainfall (2001-2017). This result reflected that there was variability in the mean growing season of rainfall between 2016 and 2017 because of the drought outbreak in Borana Zone in 2016 that had a negative impact on the rangeland ecosystem.

Temperature: Temperature is another climatic factor that affects the productivity of rangeland biodiversity. The maximum and minimum mean temperatures of 17 years (2001-2017) were taken from the nearest station at Yabello and Teltele sites while temperature data was not registered at Arero site. The monthly mean temperature of the growing season that showed in Table 2 was not significant differences between study years and sites and as well as the total means of 2001-2017 years while higher mean temperature value was recorded in Teltele site.
Sampling techniques: After the discussion held with elders and pastoralists leader of peasant association, traditional enclosure rangeland type that has the same age of enclosing period was selected side by side with continuous grazing rangeland types. Then three main plots each measuring $20 \mathrm{~m} \mathrm{x}$ $20 \mathrm{~m}$ at every $200 \mathrm{~m}$ interval on a leaner transect was used for each rangeland type [5]. Woody vegetation density, richness,

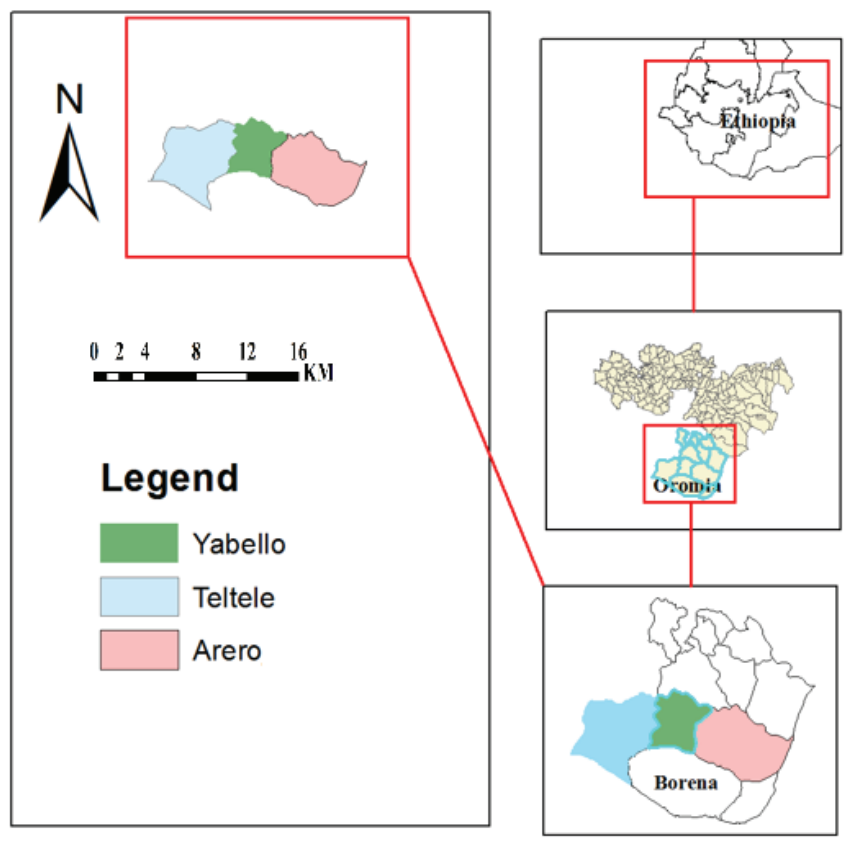

Figure 1: Map descriptions of Study Areas

Table 1: Seventeen years (2001-2017) monthly rainfall ( $\mathrm{mm}$ ) of plant growing season (long and short rain season) of study sites (Arero, Teltele and Yabello districts).

\begin{tabular}{|c|c|c|c|c|c|c|c|c|}
\hline \multirow{2}{*}{ Element } & \multirow{2}{*}{ Year } & \multicolumn{3}{|c|}{ Long rainy season } & \multicolumn{3}{|c|}{ Short rainy season } & \multirow{2}{*}{$\begin{array}{c}\text { Sum of two rainy } \\
\text { season }\end{array}$} \\
\hline & & Mar. & Apr. & May & Sep. & Oct. & Nov. & \\
\hline \multirow{3}{*}{ Arero } & $\begin{array}{c}2001- \\
17\end{array}$ & 47.51 & 175.74 & 109.91 & 25.48 & 113.13 & 74.22 & 545.98 \\
\hline & 2016 & 56.20 & 103.20 & 56.60 & 5.00 & 0.00 & 0.00 & 221.00 \\
\hline & 2017 & 15.00 & 142.30 & 312.60 & 40.50 & 63.20 & 5.60 & 579.20 \\
\hline \multirow{3}{*}{ Teltele } & $\begin{array}{c}2001- \\
17\end{array}$ & 85.47 & 165.34 & 113.46 & 41.04 & 92.88 & 62.22 & 560.40 \\
\hline & 2016 & 40.90 & 84.80 & 55.50 & 4.00 & 0.00 & 0.00 & 185.20 \\
\hline & 2017 & 91.80 & 214.60 & 59.00 & 33.30 & 119.20 & 0.80 & 518.70 \\
\hline \multirow{3}{*}{ Yabello } & $\begin{array}{c}2001- \\
17\end{array}$ & 53.25 & 158.71 & 98.05 & 20.32 & 102.92 & 63.57 & 496.83 \\
\hline & 2016 & 50.90 & 97.50 & 69.30 & 0.00 & 0.00 & 0.00 & 217.70 \\
\hline & 2017 & 20.00 & 304.50 & 57.30 & 22.20 & 124.60 & 0.00 & 528.60 \\
\hline
\end{tabular}

Source: National Meteorological Agency of Ethiopia (NMAE).

Table 2: Seventeen years (2001-2017) monthly mean temperature of plant growing season (long and short rain season) of study sites (Arero, Teltele and Yabellodistricts) in Borana Zone, Ethiopia.

\begin{tabular}{|c|c|c|c|c|c|c|c|c|}
\hline \multirow{2}{*}{ Disrict } & \multirow{2}{*}{ Years } & \multicolumn{3}{|c|}{ Long rainy season } & \multicolumn{3}{|c|}{ Short rainy season } & \multirow{2}{*}{ Average } \\
\hline & & Mar & Apr & May & Sep & Oct & Nov & \\
\hline \multirow{3}{*}{ Teltele } & 2001-17 & 25.02 & 22.90 & 22.42 & 22.53 & 22.83 & 22.63 & 22.93 \\
\hline & 2016 & 26.00 & 23.25 & 22.85 & 23.55 & 23.25 & 24.00 & 23.70 \\
\hline & 2017 & 22.60 & 21.95 & 23.00 & 21.90 & 22.15 & 19.55 & 21.83 \\
\hline \multirow{3}{*}{ Yabello } & 2001-17 & 22.24 & 21.18 & 20.23 & 20.72 & 20.52 & 20.29 & 20.30 \\
\hline & 2016 & 21.60 & 21.60 & 19.70 & 20.55 & 21.00 & 22.00 & 20.81 \\
\hline & 2017 & 21.50 & 20.40 & 19.60 & 20.20 & 20.50 & 19.70 & 19.90 \\
\hline
\end{tabular}

Source: National Meteorological Agency of Ethiopia (NMAE)

Citation: Asfaw EJO, Zewedu T, Usmane IA (2020) Impacts of Climatic Factors on Vegetation Species Diversity, Herbaceous Biomass in Borana, Southern Ethiopia. 
and diversity of the rangelands types were determined from eighteen main plots of $20 \mathrm{~m} \times 20 \mathrm{~m}$ sizes. The attributes samples of grass and forbs species samples were collected from seventeen subplots of $1 \mathrm{~m} \times 1 \mathrm{~m}$, placed in diagonal and central line at an equal interval within the main plots. Samples of the 17 subplots pooled to represent the herbaceous species of the main plot in order to determine herbaceous species biomass, diversity, and richness. The total standing herbaceous species (grass and non-grass) biomass was clipped at $2 \mathrm{~cm}$ above ground of subplots, oven-dried at 105 oc for 24 hours and weighed by a sensitive balance in Yabello Pastoral and Dryland Agriculture Research Center of soil laboratory to determine the dry matter yield of herbages [6]. Overall, 18 main sampling plots $(20 \mathrm{~m} \times 20 \mathrm{~m})$ and 306 sub-quadrants $(1 \mathrm{~m} \times 1 \mathrm{~m})$ were established to collect the required data in study districts. To recognize the appropriate location of sampling, GPS (Global Positioning System) was used to locate the right altitude, latitude, and longitude of each sample site.

\section{Data analyses}

Plant diversity and richness of the rangeland types, analyzed using PAST version 3.10, Paleontological Statistical software [7]. To examine the impacts of climatic factors on plant species, we accomplished the relationship between annual rainfall and mean annual temperature of study sites with plant species attributes by using linear regression. All statistical analyses were performed within the SAS software (version 9.1; SAS Institute, 2002) [8]. LSD (least significant differences) test with $\mathrm{P}<0.05$ was used for means comparison.

\section{Results and discussion}

\section{Effect of climate factors on rangeland}

Effect of rainfall on plant species richness: The result revealed that mean annual rainfall was an important factor that was altering the plant species richness. On present study, the variation in herbaceous species richness of study sites was a highly significant difference $\left(\mathrm{r}^{2}=0.56, \mathrm{P}=0.0003\right)$ with a positive linear relationship to mean annual rainfall and woody species richness was significantly different $\left(r^{2}=0.31\right.$, $\mathrm{P}=0.02$ ) with a negative linear relationship (Figure 2). The retention of soil moisture available for plant growth is higher in where receiving a high amount of rainfall than a low amount of rainfall. This indicates that the herbaceous species richness was increased as increased rainfall while woody species richness was less sensitive to short periods of moisture stress. Therefore, the propagation of dormant perennial stems and germination seed of perennial and annual species can increase herbaceous richness during the available rainy season than shortage rainy season.

The reduction rainfall in amount and the increment of erratic nature of rainfall in the study areas has a great impact on herbaceous richness. This result agree with Stokes, et al. [9], who found that changes in the temporal distribution of rainfall may reduce the effectiveness of rainfall through increased variation within season (fewer, more intense rainfall events) and from year to year (more frequent drought). Zaman and Habtamu, et al. $[10,11]$, also reported that the drought increase the rate of natural died of plant root, while only health vigorous perennial grass less damage and maintain production and recover quickly on rainfall occurs.

Effect of rainfall on plant species diversity: In the semiarid environment, water availability is the main factor in the dynamics species diversity of rangeland. As result indicated, the herbaceous species diversity study area was a highly significant difference $(r=0.62, P=0.0001)$ with a positive linear relationship to mean annual rainfall while woody species diversity was a significant difference $(r=0.39, P=0.005)$ with a negative linear relationship in Figure 3. The herbaceous species diversity was increased as rainfall amount increased due to a reduction in soil moisture stress at soil surface areas that was able to use by herbaceous species root for the synthesis of their food. Woody species diversity was increased, as rainfall amount increased due to it can utilize groundwater from deep soil by their root tapes. This specifies that herbaceous species diversity is highly affected by mean annual rainfall than woody species diversity.

From this study, the most impact climatic factor that threatened the production of herbaceous species of the study sites was the mean annual rainfall of the growing season. Because the time, frequency and amount of mean annual rainfall of study areas determine the achievement of herbaceous species production. During the study, the late-onset and uneven distribution of rainfall patterns during the growing season may reduce herbaceous species regeneration than woody species. However, the herbaceous species diversity of both rangeland

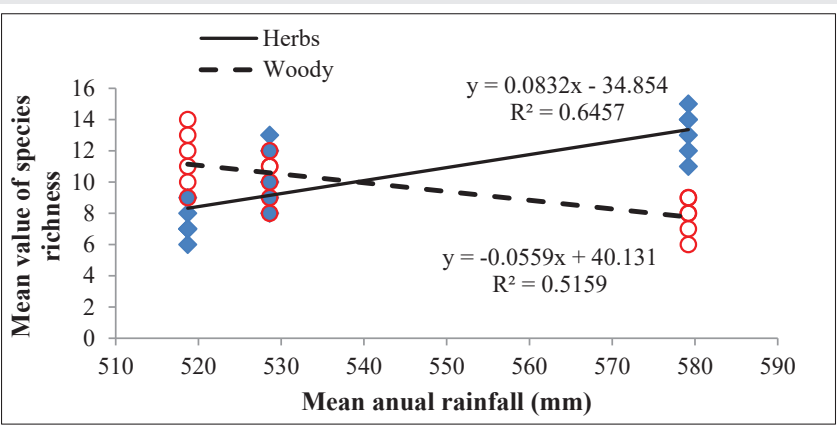

Figure 2: Effect of growing season of mean annual rainfall on plant species richness (number of species) of herbaceous and woody species ( $\mathrm{n} / \mathrm{ha}$ ) at three locations (Yabello, Teltele and Arero) during 2001-2017 in a semi-arid Borana zone in Ethiopia.

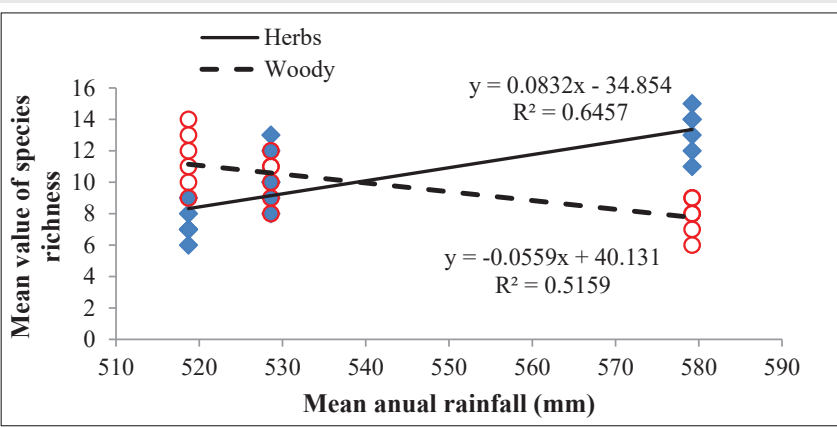

Figure 3: Effect of growing season of mean annual rainfall on plant species diversity of herbaceous and woody species ( $\mathrm{n} / \mathrm{ha}$ ) at three locations (Yabello, Teltele and Arero) during 2001-2017 in a semi-arid Borana zone in Ethiopia.

Citation: Asfaw EJO, Zewedu T, Usmane IA (2020) Impacts of Climatic Factors on Vegetation Species Diversity, Herbaceous Biomass in Borana, Southern Ethiopia. Glob J Ecol 5(1): 033-037. DOI: https://dx.doi.org/10.17352/gje.000017 
types were lower due to prolonged of dry periods in 2016 that affect the photosynthetic process of herbaceous species in both active and passive of growing season of the plants.

Effect of rainfall on dry matter of herbaceous species: The relationship between herbaceous species productivity with water availability is highly sensitive in semi-arid environments. The result has shown that the variation in herbaceous species biomass at each site was significantly difference $\left(r^{2}=0.79, p\right.$ $=0.017$ ) with a positive linear relationship to mean annual precipitation. This positive linear relationship reflects that higher biomass in a higher amount of mean rainfall of growing season (Figure 4). Since the growth performance of herbaceous species is affected by the amount of rainfall that falls in the growing season of plant species. In semi-arid of study areas, the growth performance direct influence on the herbaceous species biomass yield per hector that is increased as increased mean annual rainfall. Similarly, Dingaan, et al. [12], reported that trend of aboveground biomass increase with increasing rainfall. In the study site, the herbaceous species biomass production of rangeland type was lower than the previous find due to growth performances of herbaceous species were influenced during and after drought outbreak. Because during a drought year, the annual herbaceous species was disappeared and some perennial herbaceous species was overgrazed and even dried that weakly recovery after the drought was observed. This agreement with Cheng, et al. [13], reported that annual species was disappeared during a drought year and Stokes, et al. [9] confirmed that after drought breaks, total forage production might be lower than normal due to less plant per unit areas.

Effect of temperature on species richness and diversity: The result showed that the mean annual temperature is other climatic factor that was important on dynamics of botanical composition of rangeland. On present study, the variation in herbaceous species richness of study sites was high significantly difference $\left(r^{2}=0.67, P=0.001\right)$ with negative linear relationship to mean annual temperature and woody species richness was significant difference $\left(r^{2}=0.44, P=0.02\right)$ with negative linear relationship due seldom species regeneration in dry season. Herbaceous species diversity was significantly difference $\left(r^{2}=\right.$ $0.65, P=0.001$ ) with negative linear relationship to mean annual temperature and woody species diversity was no significant difference $\left(r^{2}=0.50, P=0.55\right)$ with negative linear relationship because woody species of study area had root tap system that encouraging less sensitive to temperature (Figure 5).

In addition, the biomass yield of herbaceous plant species of study areas was not significant difference $\left(\mathrm{r}^{2}=0.34, \mathrm{P}=\right.$ 0.41) with negative linear relationship with mean annual temperature. This indicates that herbaceous species dry matter was decreased as raised mean annual temperature due to wilting and dried occurs while the mean annual temperature was equally affect the biomass yield of study site because no variation in mean annual temperature between sites and years. This result agrees with Stokes, et al. [9], who reported that in warmer climates, increase heat stress and increase evaporation demand would likely have a negative effect on pasture. Similarly, Neil, et al. [14], reported that evaporation raises the

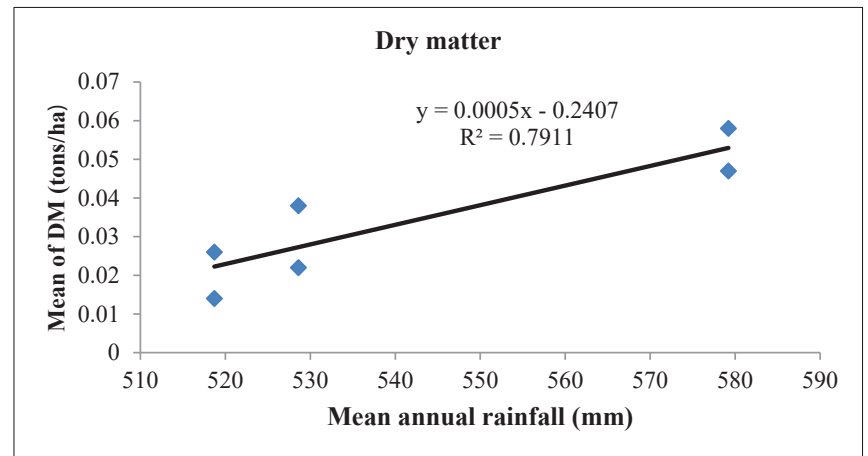

Figure 4: Effect of growing season of mean annual rainfall on herbaceous biomass yield (tons/ha) at three locations (Yabello, Teltele and Arero) during 2001-2017 in a semi-arid Borana zone in Ethiopia.
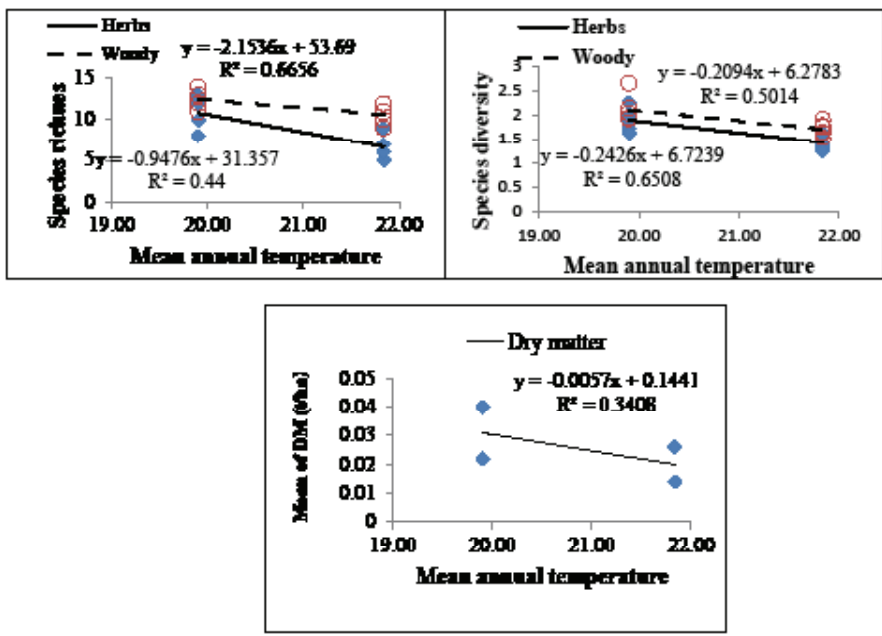

Figure 5: Effect of mean annual temperature on plant species richness and diversity of herbaceous and woody species ( $\mathrm{n} / \mathrm{ha}$ ) and on herbaceous biomass yield (tons/ ha) at three locations (Yabello, Teltele and Arero) 2001-2017 in a semi-arid Borana zone in Ethiopia.

rate of soil salinity and reduces volatile soil nutrient and wilting and dried less drought-tolerant of vegetation, which enhances the reduction of rangeland production. The air temperature of Teltele site is warmer than Yabello study areas, which lead to a high evaporation rate on available water that might have a higher impact on plant species diversity, richness, and biomass yield. Similarly, Coppock [15-17], reported that compared to rainfall, air temperatures vary much less throughout the year in most of sub-Saharan Africa, while warmer climates increase evaporation that effects on production and distribution of plant species. On the other hand, Stokes, et al. [9], also reported that the condition of climate becomes hotter and drier, pasture composition is shift to more xeric species that may be less suitable to grazing.

\section{Conclusions and recommendations}

Climatic factors special rainfall is the main factor, which was altering the botanical composition of semi-arid areas of Borana rangeland. As a recent study, the annual rainfall was positive relationships with plant species diversity, richness, and a groundcover of rangeland types. However, the mean annual temperature of study sites was negative relationships with plant species diversity, richness, and a groundcover 
of rangeland types. The increasing year-to-year variability of rainfall at the study site was altering the production of rangeland. Additionally, rangeland of study sites had been degraded in terms of botanical composition as the result of decreased in palatable herbaceous species due to increasing recurrent drought rangeland exposure for heavy grazing. Therefore, pastoralists and agropastoralists should be considered and identified the availability of rainfall either for the management of rangeland or conservation of excess feed resources for the dry period. However, further study across socio-economic factors should be investigated to capture the whole impact of rangeland ecosystem dynamics for sustainable management. Hence, loose of respective culture value, pastoralist knowledge, and pattern of livelihoods may be educed degradation of rangeland ecosystems through exposing rangeland for improper settlement, grazing, and cultivation

\section{References}

1. Holecheck JL. Pieper DR, Herbel CH (2001) Range Management Principles and Practices. Fourth edition. Reagent/prentice Hall, Englewood cliffs. New Jersey 526. Link: https://bit.ly/3fJgJ5C

2. Dadamouny MA, Schnitzler M (2015) Trends of climate with arapid change in Sinai, Egypt. Journal of Water and Climate Change 7: jwc2015215. Link: https://bit.ly/31J7Xzp

3. Hoffman TM, Vogel C (2008) CLimate change impacts on Africa rangeland Rangelands 30. Link: https://bit.ly/31IINkz

4. Hoshino A, Yoshihara Y, Sasaki T, Okayasu T, Jamsran U, et al. (2009) Comparison of vegetation changes along grazing gradients with different numbers of livestock. J Arid Environ 73: 687-690. Link: https://bit.ly/3ky3hFr

5. Dalle G (2004) Vegetation ecology, rangeland condition, and forage resources evaluation in the Borana lowlands, Southern Ethiopia. A Ph.D. Dissertation submitted to Georg-August-University. Gottingen, Germany. 241. Link: https://bit.ly/31lJhqT

6. Whalley RDB, Hardy MB (2000) Measuring botanical composition of grasslands. In: Mannetje, L.'t, and R. M. Jones. (eds.) Field and laboratory methods for grassland and animal production research. CABI Publishing, Wallingford, UK, 67-102. Link: https://bit.ly/31GxadS

7. Hammer Harper DAT, Ryan PD (2001) PAST:Paleontological Statistics Software Package for Education and Data Analysis. Palaeontologia Electronica 4: 9. Link: https://bit.ly/3afMjqm

8. SAS Institute (2002) Statistical Analysis System. Users' guide: statistics version 9.0. Cary: SAS Institute.

9. Stokes CJ, Ash A, Howden MS (2008) Climate change impacts on Australian Rangelands. Rangelands 30. Link: https://bit.ly/2XSTlg2

10. Zaman S (1997) Effects of rainfall and grazing on vegetation yield and cover of two arid rangelands in Kuwait. Environmental Conservation 24: 344-350. Link: https://bit.ly/3fQPGVQ

11. Keba HT, Madakadze IC, Angassa A, Hassen A (2013) Nutritive value of grasses in semi-arid rangelands of ethiopia: local experience based herbage preference evaluation versus laboratory analysis. Asian-Australas J Anim Sci 26: 366-377. Link: https://bit.ly/31IKluT

12. Dingaan MNV, Walken S, Tsubo M, Newby $T$ (2016) Influence of grazing on plant diversity-productivity relationship in semi-arid grassland of South Africa. Link: https://bit.ly/2DJKoP8

13. Cheng $Y$, Tsubo $M$, Ito TY, Nishihara $E$, Shinoda $M$ (2011) Impact of rainfall variability and grazing pressure on plant diversity in Mongolian grasslands. Journal of Arid Environments 75: 471476. Link: https://bit.ly/2XS64zc

14. Neil E, John M, Dale W, Mary M, Wight R, et al. (2009) Effects of climatic change on the edaphic features of arid and semiarid lands of western North America. Arid soil research and rehabilitation 8: 307-351. Link: https://bit.ly/2DQ2Jtv

15. Coppock DL (1994) The Borana Plateau of Southern Ethiopia: Synthesis of pastoral research, development, and changes 1980-90. International Livestock Center for Africa, Addis Ababa, Ethiopia. Link: https://bit.ly/2DIbru0

16. Bassi M (2003) Synthesis of lessons learned. Enhancing equity in the relationship between protected areas and local communities in the context of global change.Horn of Africa and Kenya. Link: https://bit.ly/2PJSVUB

17. Gufu $O$ (2001) Indigenous ecological knowledge of landscape change in East Africa. International Association for Landscape Ecology 19: 1-3.

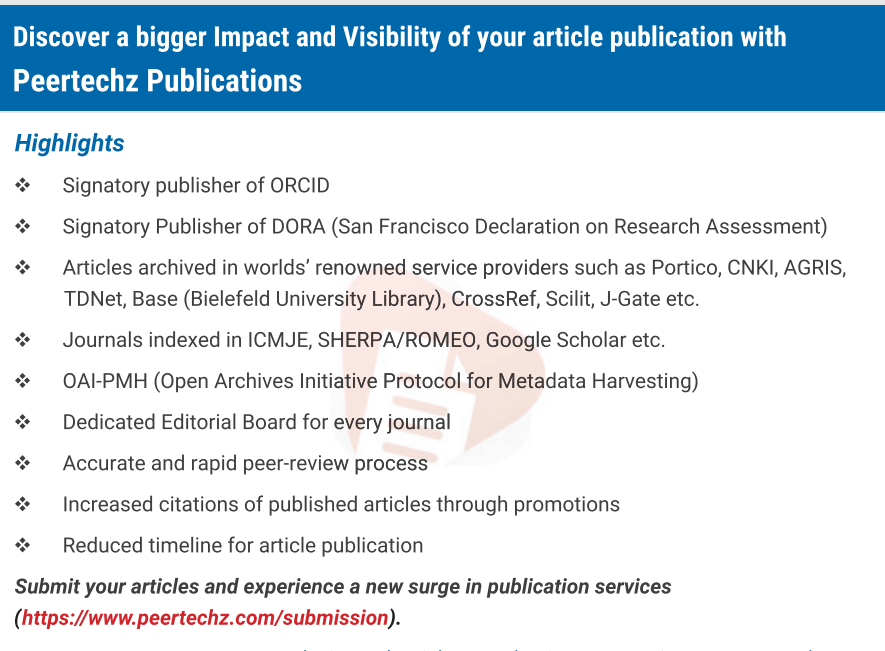

Copyright: ๑ 2020 Asfaw EJO, et al. This is an open-access article distributed under the terms of the Creative Commons Attribution License, which permits unrestricted use, distribution, and reproduction in any medium, provided the original author and source are credited. 